\title{
Análise das Condições do Comércio de Caldo de Cana em Vias Públicas de Municípios Paulistas
}

\author{
Aline Cristine Garcia de Oliveira ${ }^{1}$; Fabiana Andrea Gobbo Nogueira ${ }^{1}$; Cíntia Fernanda Pedroso Zanão ${ }^{1}$; \\ Clovis Wesley Oliveira Souza ${ }^{2}$, Marta Helena Fillet Spoto ${ }^{1}$
}

\begin{abstract}
O caldo de cana ou garapa é uma bebida saborosa, energética, não alcoólica, muito apreciada no Brasil, sendo normalmente comercializado em vias públicas por vendedores denominados garapeiros. O presente estudo teve como objetivo analisar as condições do comércio de caldo de cana em vias públicas de municípios paulistas por meio de entrevistas e de observações visuais em 70 pontos de venda das cidades de Piracicaba (22), Rio Claro (05), São Carlos (21), Sumaré (14), Águas de São Pedro (01) e São Paulo (07). Os vendedores são em sua maioria, homens, com tempo variado de atuação no ofício e escolaridade com predominância do ensino fundamental. A maioria dos garapeiros fabrica o gelo domesticamente, utilizando água proveniente de rede de abastecimento, promove a limpeza das mãos e das moendas apenas com água, utiliza copos descartáveis para a comercialização da bebida e tem remuneração mensal superior a um salário mínimo. Mais da metade dos vendedores entrevistados desconhece o rol de doenças veiculadas por alimentos e todos afirmaram ter interesse em receber orientações sobre práticas higiênico-sanitárias de manipulação de alimentos. O deficiente preparo profissional de alguns manipuladores, aliado ao desconhecimento de condições higiênico-sanitárias adequadas e indisponibilidade de infra-estrutura, foram considerados fatores de risco para a contaminação do caldo de cana. Considerando-se a Resolução RDC no 218, de 29 de julho de 2005, os pontos de venda devem se adequar em vários aspectos para atender às condições higiênico-sanitárias necessárias para a comercialização da bebida em condições que assegurem sua qualidade.
\end{abstract}

Palavras-chave: segurança do alimento, caldo de cana, alimentos de rua.

\section{Safety Analysis of Sugarcane Juice Vending in Public Ways of Municipal Districts of São Paulo State}

Sugarcane juice or "garapa" is a tasty, energetic, non-alcoholic drink, highly appreciated in Brazil, but normally marketed in public roads. The aim of this work was to verify the conditions of the trade of sugarcane juice in public district roads in São Paulo state by means of interviews and visual observations in 70 vending points in Piracicaba (22), Rio Claro (5), São Carlos (21), Sumaré (14), Águas de São Pedro (1) and São Paulo city (7). Sales are primarily done by men, with varying degrees of education and time of experience in the profession. Most of them produce the ice in their own homes, using tap water, hygienize hands and mills with plain water. They use disposable cups to serve the juice and have incomes higher than the national minimum wage. Most of them have no knowledge of food-borne diseases, but all acknowledged to be interested in receiving training about hygienic-sanitary practices of food manipulation. The lack of professional training of some manipulators and the lack of knowledge on the appropriate hygienic-sanitary conditions and infrastructure were considered risk factors for the contamination of the sugarcane juice sold. In order to meet the standards set forth

${ }^{1}$ Departamento de Agroindústria, Alimentos e Nutrição (ESALQ/USP)

${ }^{2}$ Departamento de Morfologia e Patologia. Centro de Ciências Biológicas e da Saúde (UFSCar) 
by Resolution RDC no. 218, of July 29, 2005, the sites for sugarcane juice vending should be adapted in various aspects before the minimal hygiene-sanitary quality of this popular drink could be assured.

Key-Words: food safety, sugarcane juice, street vending of foods.

\section{Introdução}

Devido às intensas mudanças no estilo de vida, um expressivo número de pessoas consome alimentos comercializados fora do domicílio, em estabelecimentos fixos ou distribuídos por ambulantes. Entre diversos aspectos, a distância entre o domicílio e os locais de trabalho, aliada às dificuldades de transporte e de locomoção nos grandes centros, são considerados os fatores determinantes deste comportamento [1]. Estima-se que $25 \%$ a $30 \%$ do gasto familiar nos grandes centros urbanos da América Latina destina-se ao consumo de alimentos comercializados nestes estabelecimentos [2].

O comércio de alimentos de rua, originário da Ásia, da América Latina e da África disseminouse rapidamente em muitos países da Europa e da América do Norte. O termo "alimentos de rua" é definido como uma variedade de alimentos e bebidas prontos para consumo, preparados e/ou comercializados em locais públicos, principalmente nas ruas. Este tipo de alimento apresenta vantagens, como menor preço, quando comparado àqueles alimentos ou refeições comercializados pelos restaurantes, além da conveniência e grande variedade de opções atrativas ao consumidor [3].

O comércio de alimentos de rua apresenta aspectos positivos, devido à sua importância socioeconômica, cultural e nutricional, e negativos relacionados às questões higiênico-sanitárias [4]. Os estabelecimentos de preparo e comércio de alimentos assumem um papel importante na qualidade da alimentação da população, principalmente urbana, que, em decorrência do tempo disponível para a preparação e a ingestão de alimentos, prefere refeições mais rápidas, tanto no que diz respeito à aquisição e preparo quanto ao consumo [1].

Os pontos de venda de alimentos nas ruas apresentam uma grande diversidade de formas, dimensões, materiais de construção e facilidades sanitárias disponíveis. Existem aqueles que envolvem, por exemplo, uma simples cesta, mesa ou cadeira de madeira, até os pontos construídos com metal e equipados com eletricidade, abastecimento de água e refrigeração [5]. Em geral, as instalações são precárias, não dispondo de sanitários, de rede de energia elétrica e de sistema de abastecimento de água potável, o que dificulta a higienização das mãos e dos utensílios utilizados no preparo das refeições e a manutenção da temperatura adequada dos alimentos preparados. A água residuária e o lixo muitas vezes são descartados próximo ao local, o que atrai insetos e roedores.

As precárias condições higiênico-sanitárias do local, aliadas à falta de treinamento e conhecimento dos vendedores sobre manipulação de alimentos, podem representar riscos à saúde da população, devido ao fato dos alimentos poderem ser facilmente contaminados por microrganismos $[6$, $7,8]$.

Em razão das adversidades econômicas brasileiras, cresce cada vez mais a procura por alternativas viáveis de subsistência, como é o caso, por exemplo, do comércio de rua. Devido à oferta limitada de emprego, falta de qualificação profissional, processo de urbanização, deterioração do poder aquisitivo e necessidade de sobrevivência, a população busca alternativas para a obtenção de renda no comércio informal, incluindo a venda de alimentos em vias públicas [9]. Este setor da economia tem crescido substancialmente nas últimas décadas, juntamente com a crescente urbanização e o aumento da população [3, 6]. Segundo Arambulo III et al. (1995), a venda de alimentos nas ruas da América Latina envolve, direta ou indiretamente, mais de um milhão de pessoas [10].

A comercialização de alimentos nas ruas apresenta vários atrativos, dentre os quais o pequeno 
investimento financeiro para iniciar o negócio, o não recolhimento de tributos decorrente da atuação no mercado informal, a determinação do que vender e o horário de trabalho $[6,11]$. Estima-se que cerca de $70 \%$ a $80 \%$ dos vendedores de alimentos que atuam em vias públicas pertencem ao grupo da população economicamente ativa, sendo a rentabilidade mensal superior a um salário mínimo, o que demonstra a importância deste setor para a economia [2].

Pesquisas, tendo por base alimentos comercializados em vias públicas em vários países na América Latina, apontam para o potencial de tais alimentos em ocasionar distúrbios gastrointestinais em função da presença de microrganismos patogênicos, devido às más condições higiênicas, associadas a temperaturas ambientais elevadas [12, 13]. No Brasil, estudos realizados em diversas regiões, envolvendo alimentos comercializados em vias públicas, demonstraram que este tipo de produto pode representar um risco à saúde da população $[8,14,15,16,17,18,19]$.

Geralmente os alimentos vendidos nas ruas são produtos prontos para o consumo, preparados no próprio local de comercialização, situado, principalmente, em regiões de grande afluência do público, tais como: mercados, ponto de ônibus, escolas, jardins, entrada de hospitais, praças e feiras $[6,16,20,21]$. O perfil dos consumidores deste tipo de alimento é diversificado. Freqüentemente, os consumidores procuram refeições completas, refrescos ou lanches a baixo custo e rapidez no preparo e, inicialmente, estão preocupados com o preço, a conveniência e o sabor e, em seguida, com a inocuidade e a qualidade nutricional dos produtos consumidos [22,23,24].

Os produtos comercializados diferem de acordo com os países e culturas, podendo assumir grande importância do ponto de vista turístico, pois vários são produtos típicos de uma região, sendo muito procurados e apreciados pelos turistas [18]. O consumo de alimentos vendidos nas ruas é um hábito disseminado mundialmente e como exemplos podem ser citados a sardinha na brasa de Portugal, os chás na Índia, os crepes na França, ceviche no Peru, o cachorro-quente na Guatemala, o chat no Paquistão, a carne assada, o caracol frito, o peixe e a cana-de- açúcar na África. No Brasil, encontramos vendedores de biju, puxa-puxa, cachorro-quente, pastel, acarajés, tapiocas, churros, coco verde, pamonha, caldo de cana, entre outros $[9,22,25,26]$.

O caldo de cana ou garapa é uma bebida energética, não alcoólica, que possui sabor agradável, sendo muito popular no Brasil, devido às suas características de refrescância e sabor doce. Tal bebida é consumida freqüentemente por pessoas de todas as idades e classes sociais, especialmente nos períodos mais quentes do ano. O caldo é obtido por moagem da cana-de-açúcar em moendas elétricas ou manuais, coado em peneiras metálicas e servido com gelo, podendo ser consumido puro ou adicionado de suco de frutas ácidas, sendo normalmente comercializado por vendedores ambulantes, denominados garapeiros, em vias públicas, parques, praças e feiras $[14,27,28]$.

Esta bebida é caracterizada como um líquido opaco, de coloração que varia de parda ao verde escuro, viscoso, cuja composição química é variável em função da variedade, idade e sanidade da canade-açúcar. O liquido preserva todos os nutrientes presentes na cana, entre eles minerais (3\% a $5 \%$ ) como ferro, cálcio, potássio, sódio, fósforo, magnésio, além de vitaminas do complexo B e vitamina C. Os principais componentes são água, cuja composição varia entre $65 \%$ e $75 \%$, e sacarose, correspondendo a $70 \%$ a $91 \%$ do total de sólidos solúveis. A cana-deaçúcar contém ainda glicose $(2 \%$ a $4 \%)$, frutose $(2 \%$ a $4 \%$, proteínas $(0,5 \%$ a $0,6 \%)$, amido $(0,001 \%$ a $0,05 \%)$, ceras e ácidos graxos $(0,05 \%$ a $0,015 \%)$ e pigmentos $(3 \%$ a $5 \%$ ) [29,30].

O caldo de cana-de-açúcar, por conter várias quantidades de nutrientes orgânicos e inorgânicos, alta atividade de água, $\mathrm{pH}$ entre 5,0 e 5,5 e temperatura de 25 a $30^{\circ} \mathrm{C}$, é considerado um ótimo substrato para o crescimento de uma grande flora microbiana [31]. Os microrganismos de importância a serem considerados em estudos envolvendo o caldo de cana são, essencialmente, aqueles oriundos do solo e de vegetais, dentre os quais se destacam os bolores, as leveduras, as bactérias lácticas e esporuladas [32].

No caldo extraído da cana, os microrganismos podem ser originados não só da cana como também 
de focos de contaminação nas moendas e em outros equipamentos [33]. Os manipuladores de alimentos assumem também importante papel ao atuarem como fonte de disseminação de microrganismos patogênicos [34], sendo um grupo de relevância epidemiológica na transmissão de enteropatógenos [35].

A comercialização do caldo de cana é considerada uma atividade lucrativa pelos profissionais do ramo. Em entrevista ao jornal O Estado de São Paulo, João José Perone, que há cerca de 30 anos tem atuação como garapeiro na cidade de Ribeirão Preto-SP, relata estar satisfeito com a atividade profissional, na qual obtém lucratividade de $30 \%$ [36].

$\mathrm{Na}$ literatura brasileira, existe escasso volume de pesquisas que avaliam o comércio de caldo de cana. Soccol et al. (1990) analisaram 100 amostras de caldo de cana adicionadas ou não de suco de limão, provenientes de 50 pontos de venda na cidade de Curitiba-PR. Os autores verificaram que 78\% $(n=$ 39) dos estabelecimentos mostraram-se em desacordo com as especificações legais vigentes na época. As amostras apresentaram contagem de coliformes fecais acima de $10 / \mathrm{mL}$, limite máximo permitido pela Portaria no 01 , de 28 de janeiro de 1987. Foi observado também que a alteração do pH do caldo, pela adição de suco de limão, ocasionou diminuição da presença de coliformes fecais e E.coli [14].

Kitoko et al. (2004) avaliaram a qualidade microbiológica de amostras de caldo de cana comercializadas em 50 estabelecimentos de VitóriaES e constataram que $96 \%$ deles apresentaram-se em desacordo com os padrões legais vigentes pela Resolução RDC nํ 12, de 02 de janeiro de 2001, revelando a existência de condições higiênicosanitárias deficientes no processo de obtenção do caldo de cana comercializado. O Número Mais Provável (NMP) de coliformes fecais variou entre $4,3 \times 10^{1} / \mathrm{mL}$ e $2,4 \times 10^{4} / \mathrm{mL}$ e a contagem de bolores e leveduras variou de $1,6 \times 10^{5}$ a 7,6x10 $\mathrm{UFC} / \mathrm{mL}$. O gelo utilizado para resfriar a bebida foi analisado microbiologicamente em 25 pontos de venda e verificou-se que o NMP $/ 100 \mathrm{~mL}$ de coliformes fecais variou entre 1,1 e 79, sugerindo que o gelo contribuiu para os expressivos níveis de contaminação do caldo resfriado, porém não constitui o principal foco da contaminação, visto que o NMP encontrado no gelo foi relativamente baixo [19].

Oliveira et al. (2006) avaliaram 24 pontos de venda ambulante de caldo de cana na cidade de São Carlos-SP e constataram que $25 \%$ das amostras analisadas revelaram-se em condições sanitárias insatisfatórias para consumo humano por apresentarem níveis de coliformes termo-tolerantes a $45^{\circ} \mathrm{C}$ acima do limite máximo permitido pela Resolução RDC nㅜ 12, de 02 de janeiro de 2001. Entre as amostras de caldo de cana analisadas não foi detectada a presença de Salmonella sp nem de parasitos. Foram identificados coliformes termotolerantes a $45^{\circ} \mathrm{C}$ em $31 \%$ das análises da microbiota da superfície das mãos dos vendedores participantes da pesquisa [17].

$\mathrm{Na}$ literatura são registrados alguns relatos referentes a toxinfecções alimentares envolvendo o caldo de cana. Em 1981, na Índia, uma epidemia de cólera foi atribuída ao consumo de caldo de cana com gelo contaminado. Em 1991, em Catolé do Rocha-PB, foram descritos 26 casos agudos de doença de Chagas provocados pela ingestão do caldo de cana contaminado por dejetos do barbeiro, os quais continham o Trypanosoma cruæi [37]. Em 2005, a ingestão do caldo de cana comercializado em Navegantes-SC foi associado novamente ao surto de doença de Chagas, ocasionando cinco óbitos [38].

Considerando a suspeita de ocorrência de surto de doença de Chagas aguda transmitida por alimentos contaminados com Trypanosoma cruzi $i$ e a importância da adoção de critérios de boas práticas relacionados ao beneficiamento, armazenamento, distribuição de vegetais e ao preparo e comercialização de água de coco, caldo de cana, polpas e saladas de frutas, suco de frutas e hortaliças, vitaminas ou batidas de frutas e similares, foi instituída a Resolução RDC no 218, de 29 de julho de 2005 [39], que dispõe sobre o regulamento técnico de procedimentos higiênico-sanitários para manipulação de alimentos e bebidas preparados com vegetais.

Face ao exposto e diante de lacunas de 
dados sobre o tema, este estudo teve como objetivos obter informações e analisar as condições do comércio de caldo de cana em vias públicas de municípios paulistas, tendo por base os vendedores e os locais de comercialização das cidades de São Carlos, Rio Claro, Piracicaba, Sumaré, Águas de São Pedro e São Paulo. As informações visaram caracterizar os vendedores, atribuindo ênfase aos dados relativos ao gênero, escolaridade, tempo de experiência na profissão, além das condições e noções higiênico-sanitárias e observações dos locais de comercialização diante da adequação às disposições da Resolução RDC no 218, de 29 de julho de 2005.

\section{Material e Métodos}

Para o levantamento dos conhecimentos higiênico-sanitários que os vendedores de caldo de cana possuíam e adotavam durante o seu trabalho foram realizadas 70 entrevistas, aplicando-se um roteiro previamente estruturado, baseado na Resolução RDC no 218, de 29 de julho de 2005. O roteiro (ANEXO I) envolveu questões objetivas e dissertativas relativas à caracterização dos vendedores e do local de comercialização da bebida. O roteiro foi adotado para obtenção dos dados em 70 pontos de venda dos seguintes municípios do estado de São Paulo: Piracicaba (22), Rio Claro (05), São Carlos (21), Sumaré (14), Águas de São Pedro (01) e São Paulo (07). Foram também realizadas observações visuais dos pontos de venda, dos manipuladores, da matériaprima, dos equipamentos e dos utensílios empregados para o preparo do caldo de cana. Procurou-se caracterizar esta classe de vendedores por meio da obtenção de dados sócio-econômicos, experiência profissional e noções gerais sobre condições higiênico-sanitárias e doenças veiculadas por alimentos (DVAs). Foram construídos bancos de dados utilizando-se o software Microsoft ${ }^{\circledR}$ Excell.

A Resolução RDC nำ218, de 29 de julho de 2005 preconiza que os fornecedores de vegetais devem ser previamente cadastrados pelas unidades de comercialização de alimentos, devendo o cadastro conter o nome, o endereço do fornecedor e a identificação do local de origem da matéria-prima para facilitar a rastreabilidade. As matérias-primas devem ser armazenadas em recipientes e / ou sobre paletes, estrados ou prateleiras, conservados limpos e protegidos do acesso de vetores e pragas, não devendo ser armazenados em contato direto com o piso [39].

Os manipuladores de alimentos devem manter o asseio pessoal, as unhas curtas, sem esmalte ou base, não devem usar adornos, como anéis e brincos, usar cabelo preso e protegido por touca, boné ou rede, usar vestimenta apropriada, conservada e limpa. Recomenda-se a lavagem cuidadosa das mãos antes e após a manipulação de alimentos, não fumar, cantar, espirrar, tossir ou realizar outras práticas que possam contaminar o alimento durante o preparo. Os manipuladores devem adotar procedimentos que minimizem o risco de contaminação dos alimentos por meio da lavagem das mãos, do uso de luvas descartáveis, da capacitação em higiene pessoal, da manipulação higiênica e do controle de doenças veiculadas por alimentos [39].

Quanto ao local de preparo de alimentos, ele deve ser protegido, para evitar acesso de vetores e pragas, e limpo, quantas vezes sejam necessárias, durante a realização das atividades. Os equipamentos e utensílios devem estar limpos, em adequado estado de funcionamento, sem ranhuras, rachaduras, ferrugem ou outras alterações e quando em desuso devem ficar protegidos. Os vegetais utilizados no preparo do caldo de cana devem ser lavados e sanitizados e a extração do caldo de cana deverá ser realizada imediatamente antes do consumo [39].

A água utilizada na manipulação do alimento deve ser potável, e nos locais onde não esteja disponível ou não seja viável o acesso à rede de abastecimento de água, esta deverá ser armazenada em recipiente apropriado e fechado, sendo obrigatório o uso de copos descartáveis. O gelo utilizado deve ser fabricado com água potável em condições higiênico-sanitárias satisfatórias. Os resíduos devem ser freqüentemente coletados e estocados em lixeiras com tampas, em áreas específicas para esta finalidade, de modo a evitar focos de contaminação e atração de vetores e pragas [39].

\section{Resultados e discussão}

Os dados obtidos por meio da aplicação dos 
questionários junto aos vendedores de caldo de cana revelaram que o grupo é formado, em sua maioria, por homens $(77 \%)$, com escolaridade variada, mas predominância do ensino fundamental (Figura 1). O tempo de atuação na profissão revelou variação entre 21 dias e 30 anos de atividade.

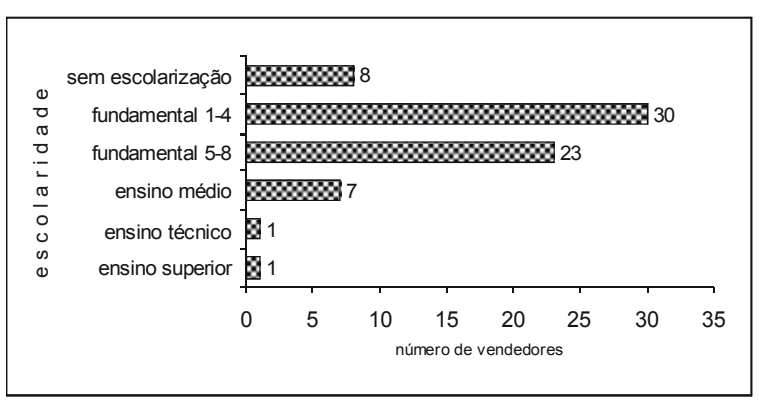

Figura 1. - Escolaridade dos vendedores de caldo de cana.

Cerca de $82 \%(n=58)$ dos vendedores declarou que comprava a cana-de-açúcar e conhecia a procedência, mencionando informações, tais como nome, endereço e identificação do fornecedor. $\mathrm{O}$ armazenamento da cana-de-açúcar após a compra é realizado por $51 \%(n=36)$ dos entrevistados no quintal de casa em área coberta e $34 \%(n=24)$ dos vendedores armazenavam no interior do estabelecimento de venda. Mais da metade dos vendedores $61 \%(n=43)$ não armazenava a canade-açúcar em contato direto com o piso, mantendoa deitada em estrados e prateleiras ou em posição vertical dentro de cestos ou baldes. Apenas dois vendedores afirmaram armazenar a cana-de-açúcar sob refrigeração.

Expressiva parcela dos vendedores (79\%) produz o gelo em casa, utilizando a água proveniente da rede de abastecimento (66\%), água de poço artesiano $(10 \%)$ e água mineral (3\%), sendo que os demais mencionaram que compravam o gelo. Cerca de $93 \%(n=65)$ mencionou que comercializava o caldo de cana em copos descartáveis. Copos de vidro foram citados pelos demais vendedores, que informaram também possuir sistema de abastecimento de água.

A higienização das mãos e dos equipamentos de extração era realizada apenas com água por $70 \%$ $(n=49)$ e $80 \%(n=56)$ dos vendedores, respectivamente. Entre os entrevistados, 94\% $(n=$ 66) mencionaram higienizar as mãos nos intervalos entre uma venda e outra. Os demais vendedores disseram proceder à higiene das mãos com freqüência de, aproximadamente, duas a cinco vezes ao dia. A limpeza dos equipamentos de moagem e utensílios era realizada uma vez ao dia por $66 \%(n=46)$ dos vendedores e os demais mencionaram proceder à limpeza, dependendo do fluxo de consumidores, com freqüência de duas ou mais vezes ao dia.

Quando indagados sobre o tempo máximo que o caldo de cana, após extraído, permanecia exposto à temperatura ambiente à espera de outro consumidor, $69 \%(n=48)$ mencionaram descartálo ou deixar no máximo 5 minutos. Menor proporção, $20 \%(n=14)$, informou que deixava o produto por um período entre 5 e 15 minutos, $6 \%(n=4)$ de 15 a 30 minutos, $4 \%(n=3)$ de 30 a 60 minutos e apenas um vendedor citou que mantinha a bebida por mais de uma hora sem refrigeração.

Quanto ao local de preparo de alimentos, 78\% $(n=55)$ dos estabelecimentos não apresentavam proteção para evitar o acesso de vetores e pragas. Os equipamentos de moagem e utensílios utilizados na preparação do caldo de cana estavam, em 56\% (n =39) dos pontos de venda, em adequado estado de funcionamento, aparentemente limpos, sem ranhuras, rachaduras, ferrugem ou outras alterações e em $21 \%(n=15)$ dos estabelecimentos estavam protegidos quando em desuso.

O armazenamento da cana-de-açúcar em locais e condições inadequadas, aliado ao fato da matéria-prima estar quase sempre previamente descascada e exposta ao ambiente em $76 \%(n=53)$ dos estabelecimentos, foi considerado fator de risco, pelo fato da matéria-prima poder contaminar-se facilmente por meio da poeira, roedores e insetos, $\mathrm{O}$ que contribui para o aumento do número de bactérias heterotróficas e de coliformes.

Cerca de 77\% $(n=54)$ dos vendedores recolhia os resíduos produzidos uma vez por dia e apenas $4 \%(n=3)$ mencionaram recolher duas ou mais vezes, não deixando lixo próximo ao local de venda. Apenas 
20\% dos garapeiros mencionaram reciclar os resíduos recolhidos. Como esta atividade contribui para grande produção diária de copos plásticos e de bagaço de cana, é aconselhável que os copos plásticos sejam reciclados e que o bagaço de cana seja transformado em adubo orgânico, ao invés de queimá-lo $(7 \%)$ ou destiná-lo ao lixo convencional $(60 \%)$. Cerca de 13\% $(n=9)$ dos vendedores mencionaram deixar os resíduos no local de comercialização. O descarte de lixo, de resíduos de alimentos e de água nas proximidades contribui para a proliferação de insetos e roedores, que são potenciais veiculadores de doenças [10]. A ausência de lixeira foi constatada em 50\% $(n=35)$ dos estabelecimentos e a presença destes recipientes com tampas foi observada em apenas 13\% $(n=9)$ dos locais de venda.

Tendo por base as observações realizadas nos pontos de venda, verificou-se que $86 \%(n=60)$ dos manipuladores de alimentos possuíam unhas curtas, sem esmalte ou base; 77\% $(n=54)$ não usavam adornos como anéis, brincos e relógio. A totalidade dos vendedores não usava maquiagem. Os cabelos presos e protegidos por touca, boné ou rede foram observados em $46 \%(n=32)$ dos vendedores e 30 $(43 \%)$ usavam vestimenta apropriada, bem conservada e limpa. Apenas quatro vendedores possuíam luvas nos estabelecimentos, mas nenhum deles as utilizavam durante o preparo da bebida. Existem controvérsias sobre a eficácia do uso de luvas descartáveis no tocante à higiene dos alimentos, pois a luva funciona como uma barreira física, mas está sujeita a rompimentos e, ainda, pode facilitar o crescimento de microrganismos na pele. As luvas impedem a transpiração das mãos, aumentando os níveis de umidade e favorecendo o acúmulo de nutrientes necessários para o desenvolvimento de microrganismos, sendo a higienização adequada das mãos mais eficiente para a remoção ou diminuição dos referidos agentes.

Apenas 10\% $(n=7)$ dos estabelecimentos tinham acesso à rede de abastecimento de água e 7\% $(n=5)$ à energia elétrica. Em todos os locais que não dispunham de rede de abastecimento de água, esta se encontrava armazenada em recipiente apropriado e fechado. $\mathrm{Na}$ totalidade dos estabelecimentos não existia sanitários e a maioria dos vendedores $76 \%(n=53)$ mencionou utilizá-los próximo ao local de vendas.

Dentre os entrevistados, mais da metade $54 \%$ $(n=38)$ afirmou não ter conhecimento a respeito de doenças veiculadas por alimentos; $29 \%(n=20)$ mencionaram conhecer superficialmente o assunto, mas não souberam citar nome, fatores como agente etiológico, formas de contaminação e prevenção de DVAs e apenas 12 (17\%) afirmaram conhecer DVAs e, dentre estes, 9 citaram a doença de Chagas, envolvida em surtos alimentares relacionados ao caldo de cana no ano de 2005. Todos os vendedores enfatizaram que têm interesse em receber orientações sobre práticas higiênico-sanitárias de manipulação de alimentos.

Portanto, pode-se considerar, como um dos fatores de risco para a contaminação do caldo de cana, a deficiente capacitação profissional da maior parte dos manipuladores. Além disso, estes trabalhadores executam múltiplas tarefas além da manipulação de alimentos, como ocorre com $76 \%$ $(n=53)$ dos vendedores, que, por não possuírem auxiliares, manipulam o dinheiro, removem o lixo e ainda extraem o produto comercializado.

Quanto à estimativa média de faturamento mensal dos vendedores de caldo de cana, $58 \%$ dos integrantes desta pesquisa mencionaram ser superior a um salário mínimo e 36\%-revelaram ser igual a um salário mínimo. Os dados obtidos são concordantes com os registros de Costarrica \& Moron (1996) [2]. Alguns vendedores afirmaram obter rendimentos que alcançam até $\mathrm{R} \$ 800,00$ com a atividade nos meses de verão, comprovando a lucratividade do ramo.

A maioria das inadequações encontradas nesta pesquisa deve-se, principalmente, à falta de capacitação e treinamento em manipulação de alimentos, desconhecimento sobre condições higiênico-sanitárias e doenças veiculadas por alimentos e indisponibilidade de infra-estrutura, como rede de abastecimento de água, energia elétrica e sanitários, do que por negligência dos vendedores em adotar medidas higiênicas.

Devido à grande importância do comércio de alimentos de rua, algumas medidas deveriam ser 
adotadas, tais como: desenvolvimento e aplicação de normas sanitárias adequadas à venda de alimentos de rua, oferta de cursos de capacitação destinados a estes vendedores, especialmente pelo fato de terem revelado interesse em receber informações de como melhor proceder em suas atividades. Na cidade de Piracicaba foi observada a maior proporção $(82 \%)$ de vendedores que afirmaram já ter recebido orientações sobre práticas higiênicas, treinamento e capacitação em manipulação de alimentos e na cidade de Sumaré a menor proporção (14\%).

Goes et al. (2001) afirmaram que dentre as medidas aplicáveis na prevenção de doenças veiculadas por alimentos, a orientação sobre higiene dos alimentos para manipuladores deve ser destacada, pois a maioria das pessoas que trabalha na manipulação de alimentos possui insuficiente escolaridade. Portanto, a metodologia de programas de treinamento destinados a este público deve considerar limitações dos grupos alvo, a fim de que atinja o objetivo de compreensão e a mudança de atitudes dos indivíduos frente à sua atividade profissional [40].

Seria adequado estabelecer um sistema de vigilância sanitária e informação epidemiológica de doenças veiculadas por alimentos comercializados em vias públicas e também estimular a adoção de medidas relativas à regularização, concessão de licenças e mecanismos de controle da atividade, tendo em vista que $40 \%(n=28)$ dos vendedores mencionaram que não são cadastrados.

\section{Conclusões}

O grupo de vendedores de caldo de cana é formado, em sua maioria, por homens, com tempo variado de atuação na profissão e escolaridade com predominância do ensino fundamental. A maioria dos profissionais fabrica em casa o gelo, utilizando água proveniente de rede de abastecimento, promove a limpeza das mãos e das moendas apenas com água, utiliza copos descartáveis para a comercialização da bebida e tem remuneração mensal superior a um salário mínimo. Mais da metade dos vendedores entrevistados desconhece doenças veiculadas por alimentos e todos afirmaram ter interesse em receber orientações sobre práticas higiênico-sanitárias de manipulação de alimentos.

A deficiente capacitação profissional observada entre a maioria dos manipuladores, aliada ao desconhecimento sobre condições higiênicosanitárias adequadas e a indisponibilidade de infraestrutura, como rede de abastecimento de água e energia elétrica, foram considerados fatores de risco para a contaminação do caldo de cana.

Considerando-se a Resolução RDC nำ 218, de 29 de julho de 2005, os pontos de venda de caldo de cana deverão passar por adaptações em vários aspectos, tais como: cadastro dos fornecedores de matéria-prima, armazenamento correto da cana-deaçúcar, uso dos cabelos presos e protegidos, vestimentas apropriadas e luvas descartáveis durante a preparação da bebida, proteção do local de preparo para evitar acesso de vetores e pragas, manutenção dos equipamentos para que estejam em adequado estado de funcionamento e lixeiras com tampas, além da implementação de capacitação em manipulação higiênica dos alimentos, visando a manutenção das condições higiênico-sanitárias necessárias para a comercialização da bebida em condições que assegurem sua qualidade.

Devido à reconhecida importância do comércio de alimentos de rua, algumas medidas deveriam ser adotadas. Dentre elas podem ser citadas: o desenvolvimento e a aplicação de normas sanitárias adequadas à venda de alimentos de rua, a oferta de cursos de capacitação aos vendedores, o estabelecimento de um sistema de vigilância sanitária e informação epidemiológica de doenças veiculadas por alimentos comercializados em vias públicas e também a adoção de medidas governamentais que visem a regularização, concessão de licenças e mecanismos de controle da atividade.

\section{Agradecimentos}

A prof ${ }^{a}$. Dra . Marina Vieira da Silva pela revisão crítica da primeira versão do trabalho, apresentado na disciplina de pós-graduação sob sua responsabilidade (ESALQ/USP- segundo semestre de 2005). 


\section{Referências bibliográficas}

[1] Biasoto ACT \& Sturion GL. Ocorrência de doenças de origem alimentar em municípios paulistas. In: Agropecuária; CD de resumos do $13^{\circ}$ Simpósio Internacional de Iniciação Científica da Universidade de São Paulo; Piracicaba, São Paulo: SIICUSP; 2005.

[2] Costarrica ML \& Morón C. Estrategias para el mejoramiento de la calidad de los alimentos callejeros em América Latina y el Caribe. Food Nutrition and Agriculture. 1996; 17/18: 47-57.

[3] Wirnano FG \& Allain A. Street foods in developing countries: lessons from Asia. Food Nutrition and Agriculture. 1991; 1:(1), 11-18.

[4] Yasmeen G. Workers in the urban "informal" food sector: innovative organizing strategies. Food Nutrition and Agriculture. 2001; 29: 32-41.

[5] Huamán JP. Las tecnologías apropiadas para la venta callejera de alimentos. Food, Nutrition and Agriculture. 1996; 17/18: 62-69.

[6] Bryan FL, Michanie SC, Alvarez P, Paniagua A. Critical control points of street-vended foods in the Dominican Republic. Journal of Food Protection. 1988; 51:(5), 373-383.

[7] Silva Jr EA. Manual de controle higiênico-sanitário em alimentos. São Paulo: Varela, 1995. 479p.

[8] Lucca A \& Torres EAFS. Condições de higiene de "cachorro-quente" comercializado em vias públicas. Revista Saúde Pública. 2002; 36:(3), 350352.

[9] Germano MIS \& Germano PML. Comida de rua: prós e contras. Higiene Alimentar. 2000; 14:(77), $27-$ 33.

[10] Arambulo III P, Almeida CR, Cuéllar J, Belotto AJ. La venta de alimentos em la vía pública en América Latina. Boletin de la Oficina Sanitaria Panamericana. 1995; 118:(2), 97-107.

[11] Michanie S. Calidad microbiológica de los alimentos vendidos en las calles. La Alimentacion Latinoamericana. 1994; 203: 66-72.
[12] Bryan FL, Teufel P, Riaz S, Roohi S, Qadar F, Malik ZR. Hazards and critical control points of street-vending operations in a Mountain Resort town in Pakistan. Journal of Food Protection. 1992a; 55:(9), 701-707.

[13] Mosupye FM \& von Holy A. Microbiological hazard identification and exposure assessment of street food vending in Johannesburg, South Africa. International Journal of Food Microbiology. 2000; 61: 137-145.

[14] Soccol CR, Schwab A, Katsoka CE. Avaliação microbiológica do caldo de cana (garapa) na cidade de Curitiba. Boletim do Centro de Pesquisa e Processamento de Alimentos. 1990; 8:(2), 116-125.

[15] Catanozi MPLM, Morelhão GG, Iurcic KM. Avaliação microbiológica de lanches vendidos em carrinhos de ambulantes na cidade de Araraquara, SP. Higiene Alimentar. 1999; 13:(66/67), 116-121.

[16] Garcia-Cruz CH, Hoffmann FL, Bueno SM. Monitoramento microbiológico de lanches vendidos por ambulantes na parte central da cidade de São José do Rio Preto, SP. Higiene Alimentar. 2000; 14:(75), 48-51.

[17] Oliveira ACG, Seixas ASS, Sousa CP, Souza CWO. Microbiological evaluation of sugarcane juice sold at street stands and juice handling conditions in São Carlos, São Paulo, Brazil. Cadernos de Saúde Pública. 2006; 22:(5), 1111-1114.

[18] Rodrigues KL, Gomes JP, Conceição RCS, Brod CS, Carvalhal JB, Aleixo JAG. Condições higiênicosanitárias no comércio ambulante de alimentos em Pelotas-RS. Ciência e Tecnologia de Alimentos. 2003; 23:(3), 447-452.

[19] Kitoko PM, Oliveira AC, Silva ML, Lourenção M, Aguiar EF. Avaliação microbiológica do caldo de cana comercializado em Vitória, Espírito Santo, Brasil. Higiene Alimentar. 2004; 18:(119), 73-77.

[20] Bryan FL, Teufel P, Riaz S, Roohi S, Qadar F, Malik ZR. Hazards and critical control points of vending operations at a railway station and bus station in Pakistan. Journal of Food Protection. 1992b; 55:(7), 534-541. 
[21] Chakravarty I \& Canet C. Street foods in Calcutta. Food, Nutrition and Agriculture. 1996; 17/ 18: 30-37.

[22] Freese E, Romero-Abal ME, Solomons NW. The street food culture of Guatemala city: a case study from downtown, urban park. Archivos Latinoamericanos de Nutricion. 1998; 48:(2), 95-103.

[23] Canet C \& N'Diaye C. L'alimentation de rue en Afrique. Alimentation, Nutrition et Agriculture. 1996; 17/18: 4-13.

[24] Umoh VJ \& Odoba MB. Safety and quality evaluation of street foods sold in Zaria, Nigeria. Food Control. 1999; 10: 9-14.

[25] Bryan FL, Teufel P, Riaz S, Roohi S, Qadar F, Malik ZR. Hazards and critical control points of street-vended Chat, a regionally popular food in Pakistan. Journal of Food Protection. 1992c; 55:(9), 708-713.

[26] Ekanem EO. The street food trade in Africa: safety and social environmental issues. Food Control. 1998; 9:(4), 211-215.

[27] Lubatti MRS. Vendedor ambulante, profissão folclórica: pesquisa nas ruas, parques e jardins de São Paulo. Jangada Brasil. 1999; 7:1-2.

[28] Prati P, Moretti RH, Cardello HMAB. Elaboração de bebida composta por mistura de garapa parcialmente clarificada-estabilizada e sucos de frutas ácidas. Ciência e Tecnologia de Alimentos. 2005; 25:(1), 147-152.

[29] IBGE. INSTITUTO BRASILEIRO DE GEOGRAFIA E ESTATÍSTICA. Estudo nacional da despesa familiar: Tabela de composição de alimentos. 5ed. Rio de Janeiro: Varela, 1999. 137p.

[30] Fava AR. Atletas ingerem garapa para repor energia. Jornal da Unicamp. 2004; 18:(250), 8.

[31] Gallo CR \& Canhos VP. Contaminantes bacterianos na fermentação alcoólica - Revisão. STAB. Açúcar, Álcool e Subprodutos. 1991; 9:(4/5), 35-40.

[32] Gallo CR. Determinação da microbiota bacteriana de mosto e de dornas de fermentação alcoólica. [tese]. Campinas: Universidade Estadual de Campinas; 1989. 388p.

[33] Silva N \& Canhos VP. Caracterização da microbiota bacteriana contaminante do caldo de cana durante a etapa de resfriamento em torre no processo de produção de álcool. Coletânea do Instituto de Tecnologia de Alimentos. 1990; 20:(1), 60-72.

[34] Vanzo SP \& Azevedo RVP. Detecção de S. aureus em manipuladores de alimentos: perfil de resistência a antibióticos e quimioterápicos. Higiene Alimentar. 2003; 17:(101/105), 114-123.

[35] Lourenço AEP, Uchoa CMA, Bastos OMP. Enteroparasitoses em manipuladores de alimentos de hospitais da cidade de Niterói, RJ, Brasil. Higiene Alimentar. 2002; 16:(97), 16-21.

[36] Brás H. Nova fonte de renda: cana para garapa. O Estado de São Paulo, São Paulo, 27.08.2003. Suplemento Agrícola.

[37] Shikanai-Yasuda MA, Marcondes CB, Guedes LA, et al. Possible oral transmission of acute Chagas' disease in Brazil. Revista Instituto Medicina Tropical de São Paulo. 1991; 33: 351-357.

[38] Ianni BM, Mady C. Como era gostoso o meu caldo de cana... Arquivos Brasileiros de Cardiologia. 2005; 85:(6), 379-381.

[39] Brasil. Resolução RDC no 218, de 29 de julho de 2005. Dispõe sobre o regulamento técnico de procedimentos higiênico-sanitários para manipulação de alimentos e bebidas preparados com vegetais. Diário Oficial da União, Brasilia.

[40] Goes J. et al. Capacitação dos manipuladores de alimentos e a qualidade da alimentação servida. Higiene Alimentar. 2001; 15:(82), 20-22.

\section{Autores}

Aline Cristine Garcia de Oliveira - Bióloga, Mestranda da Universidade de São Paulo - Escola Superior de Agricultura "Luiz de Queiroz" - Departamento de Agroindústria, Alimentos e Nutrição

Correspondência: Rua Máximo Biondo, 574, Centro, SumaréSP. CEP: 13170-190. alinecgarcia@yahoo.com.br 
Fabiana Andrea Gobbo Nogueira - Engenheira de Alimentos, Mestranda da Universidade de São Paulo Escola Superior de Agricultura "Luiz de Queiroz" Departamento de Agroindústria, Alimentos e Nutrição

Cíntia Fernanda Pedroso Zanão - Nutricionista, Mestranda da Universidade de São Paulo - Escola Superior de Agricultura "Luiz de Queiroz" Departamento de Agroindústria, Alimentos e Nutrição
Clovis Wesley Oliveira Souza - Professor Doutor da Universidade Federal de São Carlos - Centro de Ciências Biológicas e da Saúde - Departamento de Morfologia e Patologia

Marta Helena Fillet Spoto - Professora Doutora da Universidade de São Paulo - Escola Superior de Agricultura "Luiz de Queiroz" - Departamento de Agroindústria, Alimentos e Nutrição 


\section{Anexo I}

Questionário para avaliação das condiçöes e noçöes higiênico-sanitárias que os vendedores de caldo-de-cana possuem e adotam durante o trabalho

Nome: Local: Data: Sexo: ( ) F ( ) M

1) Qual a sua escolaridade?

a) Sem escolarizaçăo.

b) Ensino fundamental $\left(1^{a}-4^{a}\right)$.

c) Ensino fundamental $\left(5^{a}-8^{a}\right)$.

d) Ensino médio.

e) Ensino técnico.

f) Ensino superior.

2) Há quanto tempo comercializa caldo-de-cana?

3) Quanto à procedência da cana-de-açúcar utilizada na preparaçắo do caldo-de-cana:

a) É o (a) senhor (a) mesmo (a) quem planta.

b) É comprada e o (a) senhor (a) desconhece a procedência.

c) É comprada e o (a) senhor (a) conhece a procedência. (Nome, endereço, identificaçăo do fornecedor)

d) Outro. Especificar

4) De posse da cana-de-açúcar, como ela é armazenada até a preparaçấo do caldo-de-cana?

a) Dentro de sua casa. Em contato direto com o piso ( ) sim ( ) não

b) No quintal de sua casa coberto. Em contato direto com o piso ( ) sim ( ) năo

c) Dentro do estabelecimento de venda. Em contato direto com o piso ( ) sim ( ) năo

d) Outro. Especificar.

5) Qual a procedência do gelo usado na preparaçăo do caldo-de-cana?

a) É fabricado em casa, com utilizaçăo de água proveniente de

b) É fabricado no local de venda, com água proveniente de

c) É comprado.

d) Outro.

6) Para a venda do produto o (a) senhor (a) utiliza:

a) Copos de vidro, apenas.

b) Copos de vidro e descartáveis.

c) Copos descartáveis, apenas.

d) Outro. Especifique

7) Qual a frequência com que promove a limpeza da moenda?

a) Duas vezes ou mais ao dia.

b) Diária (1 vez ao dia).

c) Um dia sim, outro năo.

d) Semanalmente.

e) Outro.
8) No processo de limpeza da moenda é utilizado:

a) Água, apenas.

b) Água e sabăo.

c) Água e detergente.

d) Água e álcool.

e) Água + detergente + álcool.

f) Outro. Especifique

9) Qual a frequência com que higieniza as măos para a preparação do caldo?

a) Não higienizo (vai para a questão 11)

b) 1 vez ao dia.

c) Aproximadamente de 2 a 5 vezes ao dia.

d) Entre uma venda e outra.

e) Outro. Especifique

10) Como é realizada a higiene das măos pelo (a) senhor (a)?

a) Com água.

b) Guardanapo úmido.

c) Água + sabăo.

d) Água + detergente.

e) Água + álcool.

f) Água + sabăo + álcool.

g) Outro. Especifique

11) Qual a frequência com que o lixo é recolhido?

a) 2 ou mais vezes ao dia.

b) 1 vez ao dia.

c) Um dia sim, outro não.

d) 3 vezes por semana.

e) Năo recolho.

12) Qual o destino dos residuos recolhidos?

a) Lixo convencional.

b) Reciclagem.

c) Queima.

d) Deixa no local.

e) Outro.

13) Qual o tempo máximo que o caldo-de-cana pronto para consumo permanece em temperatura ambiente à espera de outro consumidor?

a) De 0 a 5 minutos.

b) De 5 a 15 minutos.

c) De 15 a 30 minutos.

d) De 30 a 60 minutos.

e) De 60 a 90 minutos.

f) Mais de 90 minutos.

14) Onde utiliza o banheiro? 
15) Já recebeu alguma vez instruçăo da Vigilância Sanitária ou de algum outro órgăo deste tipo?
a) Năo.
b) Sim.
16) É cadastrado em algum órgăo?
a) Năo
b) Sim. Qual (is)

17) Gostaria de receber orientaçăo sobre práticas higiênico-sanitárias de manipulaçăo de alimentos?
a) Năo.
b) Sim.
c) Já recebo ou recebi orientaçăo.

18) Quantas pessoas trabalham aqui?

a) Um vendedor.

b) Um vendedor e um ajudante.

c) Um vendedor e mais de um ajudante.

d) Outro. Especificar

19) Como o(a) senhor(a) manipula o dinheiro?

a) Após manipular o dinheiro, higienizo as mãos antes de preparar outro caldo-de-cana.

b) Năo manipulo o dinheiro porque tenho ajudante para essa atividade especifica.

c) Manipulo o dinheiro e a cana-de-açúcar ao mesmo tempo e nunca tive problemas.

d) Outro.

20) Conhece sobre doenças transmitidas por alimentos?

a) Năo.

b) Conheço um pouco. Cite qual (is)

c) Sim. Cite qual (is).

21) Em seu estabelecimento, o (a) senhor (a) tem acesso à rede de abastecimento de água?

a) Sim.

b) Não.

22) Qual a estimativa média de faturamento mensal?

a) Inferior a um salário mínimo

b) Igual a um salário mínimo

c) Superior a um salário mínimo

\section{Observaçōes visuais}

23) Usa cabelo preso e protegido por touca, boné ou rede? ( ) sim ( ) năo

24) Unhas curtas, sem esmalte ou base?

( ) sim ( ) não

25) Usa maquiagem? ( ) sim ( ) não

26) Utiliza adornos? ( ) sim ( ) não

27) Usa vestimenta apropriada, conservada e limpa?

( ) sim ( ) não

28) Uso de luvas descartáveis? ( ) sim ( ) năo

29) O local de preparação é protegido para evitar acesso de vetores e pragas? ( ) sim ( ) não

30) Os equipamentos estăo limpos, utensilios em adequado estado de funcionamento, sem ranhuras, rachaduras, ferrugem ou outras alteraçōes?

( ) sim ( ) não

31) Os equipamentos de moagem e extraçăo quando em desuso ficam protegidos?

( ) sim ( ) năo

32) A cana-de-açúcar fica previamente descascada e exposta ao ambiente sem proteçăo?

( ) sim ( ) năo

33) Presença de lixeiras?

( ) năo.

( ) sim, sem tampa.

( ) sim, com tampa.

Observaçōes 